\title{
BIBECHANA
}

A Multidisciplinary Journal of Science, Technology and Mathematics ISSN 2091-0762 (Print), 2382-5340 (0nline)

Journal homepage: http://nepjol.info/index.php/BIBECHANA

Publisher: Research Council of Science and Technology, Biratnagar, Nepal

\section{Inpatients nursing care provided in a tertiary hospital of Nepal}

\author{
Heera KC ${ }^{1 *}$, Sharmila Shrestha ${ }^{2}$, Ramananda Chaudhary ${ }^{3}$, Tara Shah ${ }^{4}$, Surya B. Parajuli ${ }^{5,6}$ \\ ${ }^{1}$ Department of Nursing, Purbanchal University-Birat Health College, Biratnagar, Nepal \\ ${ }^{2}$ Department of Community Health Nursing, B. P. Koirala Institute of Health Sciences, Dharan, Nepal \\ ${ }^{3}$ Department of Child Health Nursing, B. P. Koirala Institute of Health Sciences, Dharan, Nepal \\ ${ }^{4}$ Department of Community Health Nursing, B. P. Koirala Institute of Health Sciences, Dharan, Nepal \\ ${ }^{5}$ Department of Community Medicine, Kathmandu University-Birat Medical College \& Teaching \\ Hospital, Morang, Nepal \\ ${ }^{6}$ Nepal Medical Volunteer Society, Biratnagar, Nepal \\ *E-mail: heerakc2011@gmail.com
}

Article history: Received 05 October, 2018; Accepted 05 November, 2018

http://dx.doi.org/10.3126/bibechana.v16i0.21641

This work is licensed under the Creative Commons CC BY-NC License.

https://creativecommons.org/licenses/by-nc/4.0/

\section{cc) (7) \&}

Abstract

Introduction: Nursing care is necessary for every client seeking any type of healthcare such as health promotion, diagnosis, treatment and recovery. Despite these facts, nurses are given less importance and their works are even unrecognized.

Objective: The objective of this study was to explore nursing care provided to inpatients of medical ward at B. P. Koirala Institute of Health Sciences, Dharan, Nepal.

Methodology: Hospital based cross-sectional study was carried out in medical ward of B. P. Koirala Institute of Health Sciences, Dharan from Feb 2017 to Oct 2018. Data were retrieved from inpatient admission record book of medical ward of previous 15 months from the initiation of this research work. Admission record book was reviewed and checked for completeness of the record. A total of 290 patients having complete records were enrolled. Collected data were entered in Microsoft excel and analysed by SPSS software.

Results: More than half patients (52.8\%) were male and $44.8 \%$ belonged to Janajati ethnicity. The major age group was $15-25$ years $(17.9 \%$ ) with mean and standard deviation of $49.4 \pm 20.6$. About $28.6 \%$ of the patients were admitted due to cardiovascular related problems and poisoning (13.1\%). Most of the patients $(67 \%)$ were admitted from emergency. Median duration of stay was 4 days. Every 8 out of 10 patients were recovered and discharged. General nursing care provided were maintenance of personal hygiene $(91.03 \%)$, cannula site care $(49.7 \%)$, providing psychological support $(41 \%)$, ambulation $(8.3 \%)$, back care $(7.6 \%)$, catheter care $(6.9 \%)$, passive exercise $(2.4 \%)$, chest physiotherapy $(3.7 \%)$, sponge bath $(9.3 \%)$. Specific care provided were propped-up positioning $(36.2 \%), 2$ hourly position change $(23.4 \%)$, random blood sugar monitoring $(12.4 \%), \mathrm{SpO}_{2}$ monitoring $(8.9 \%)$, watch for oxygen toxicity $(9.3 \%)$, weight monitoring $(3.1 \%)$ and pre CAG (coronary angiography) care $(2.1 \%)$.

Conclusion: Maintenance of personal hygiene, cannula site care, psychological support, two hourly positioning and oral care were the common practices performed.

Keywords: Academics and Institutes; Inpatients; Medical Ward; Nursing Care. 


\section{Introduction}

Nursing is considered as an art and a science, wherein caring forms the theoretical framework of nursing. Nursing and caring are grounded in a relational understanding, unity, and connection between the professional nurse and the patient. Care in nursing involves the application of art and science through theoretical concepts, scientific research, conscious commitment and purposeful efforts to include caring behaviors during each nurse-patient interaction [1]. The caring process is a fundamental activity of nursing that help attain, maintain, or recover optimal health and quality of life. Nurses are differentiated from other health care providers by their approach to patient care and scope of practices. Nurses practice in many specialities with differing levels of prescription authority [2]. Caring includes cognitive, affective, psychomotor and administrative skills. These skills describes the value of nursing. Nursing is a nurturing profession and caring is the essential component of its holistic practice, especially with the critically ill patient [3]. With better care environment, nurses reported more positive job experiences and patients too had significantly lower risks of death and failure $[4,5]$. Various study results indicate missed or omitted nursing care to be an independent predictor of hospital readmissions of patients [6]. For better patient outcome, electronic nursing care reminders are often being used in hospital settings to overcome the missed nursing care and aids in assessing the impact of technology on nursing practice [7]. Evidences show nursing care has led to positive patients' outcomes of morbidity and mortality across the age continuum. Despite these facts, limited attention has been given to measuring nurses' actions/behaviors in terms of care that is safe, effective, efficient, equitable, timely, and centered on patients and patients' families [4, 8]. Just as hospitals and clinicians caring for patients focus carefully on completing accurate diagnosis, appropriate and effective interventions, so do the nurses too in providing nursing care through appropriately planned nursing diagnosis. The proportion of nurses to patients, their qualifications and job description should therefore be carefully planned and managed to manage unnecessary patient death [9]. The roles of nurses have been expanded and resulted in greater job satisfaction and good patient outcome. A study conducted in Australia suggest that patients who had longer nurse consultations were more satisfied $(\mathrm{OR}=2.50,95 \% \mathrm{CI}$ : $1.43-4.35)$ and more enabled $(\mathrm{OR}=2.55,95 \% \mathrm{CI}$ : 1.45-4.50). Patients who had continuity of care with the same general practice nurse were more satisfied ( $\mathrm{OR}=2.31,95 \%$ CI: 1.33-4.00). Patients who attended practices where nurses worked with broad scopes of practice and high levels of autonomy were more satisfied (OR=1.76, 95\% CI: 1.09 2.82) and more enabled (OR=2.56, 95\% CI: 1.40-4.68) than patients who attended practices where nurses worked with narrow scopes of practice and low levels of autonomy. Patients who received nursing care for the management of chronic conditions $(\mathrm{OR}=2.64,95 \% \mathrm{CI}: 1.32-5.30)$ were more enabled than those receiving preventive health care [10]. Due to these facts of nursing care for patient satisfaction and nursing leadership, we need to know the pattern of nursing practices delivered at tertiary care hospital. In tertiary care center, many complicated referral patients are admitted which needs significant nursing care for their better prognosis. Evidence generated from this research will be helpful to formulate Standard operating procedures (SOPs) on nursing care at ward level and entire hospital level. With these facts, we aimed to explore the nursing care provided to inpatients of medical ward at B. P. Koirala Institute of Health Sciences, Dharan, Nepal.

\section{Methodology}

This was a hospital based cross-sectional study carried out in medical ward of B. P. Koirala Institute of Health Sciences, Dharan, Nepal from Feb 2017 to Oct 2018. Data were retrieved from inpatient admission record book of medical ward of previous 15 months from the initiation of this research work. Admission record book was reviewed thoroughly and checked for completeness of the record. A total of 
290 patients having complete records were enrolled for the study. Collected data were entered in Microsoft Excel and analysed by SPSS software.

\section{Results}

\section{Socio-demographic characteristics of inpatients}

In table 1, among inpatients in medical ward, more than half were male (52.8\%) and $44.8 \%$ belonged to Janajati ethnicity. The major age group among the admitted patient was 15-25 years (17.9\%) followed by $45-55$ years $(16.2 \%)$ with mean and standard deviation of $49.4 \pm 20.6$.

\begin{tabular}{|c|c|c|}
\hline Sex & Frequency & Percentage \\
\hline Male & 153 & 52.8 \\
\hline Female & 137 & 47.2 \\
\hline \multicolumn{3}{|l|}{ Ethnicity } \\
\hline Dalit & 66 & 22.8 \\
\hline Janajati & 130 & 44.8 \\
\hline Madhesi & 25 & 8.6 \\
\hline Muslim & 5 & 1.7 \\
\hline Brahmin/Chhetri & 64 & 22.1 \\
\hline \multicolumn{3}{|l|}{ Age } \\
\hline $15-25$ & 52 & 17.9 \\
\hline $25-35$ & 33 & 11.4 \\
\hline $35-45$ & 42 & 14.5 \\
\hline $45-55$ & 47 & 16.2 \\
\hline $55-65$ & 40 & 13.8 \\
\hline $65-75$ & 44 & 15.2 \\
\hline $75-85$ & 27 & 9.3 \\
\hline $85-95$ & 5 & 1.7 \\
\hline Mean \pm SD & & \\
\hline
\end{tabular}

As depicted by figure 1, majority of inpatients attending at B.P. Koirala Institute of Health Sciences were from Sunsari (35.2\%), Jhapa (15.9\%) and Morang (15.2\%) district. In figure 2, $28.6 \%$ of the patients were admitted due to cardiovascular related problems followed by poisoning $(13.1 \%)$. Majority $(66.5 \%)$ of patient were admitted in medical ward from emergency $(66.5 \%)$ and OPD $(14.8 \%)$ (table 2). 


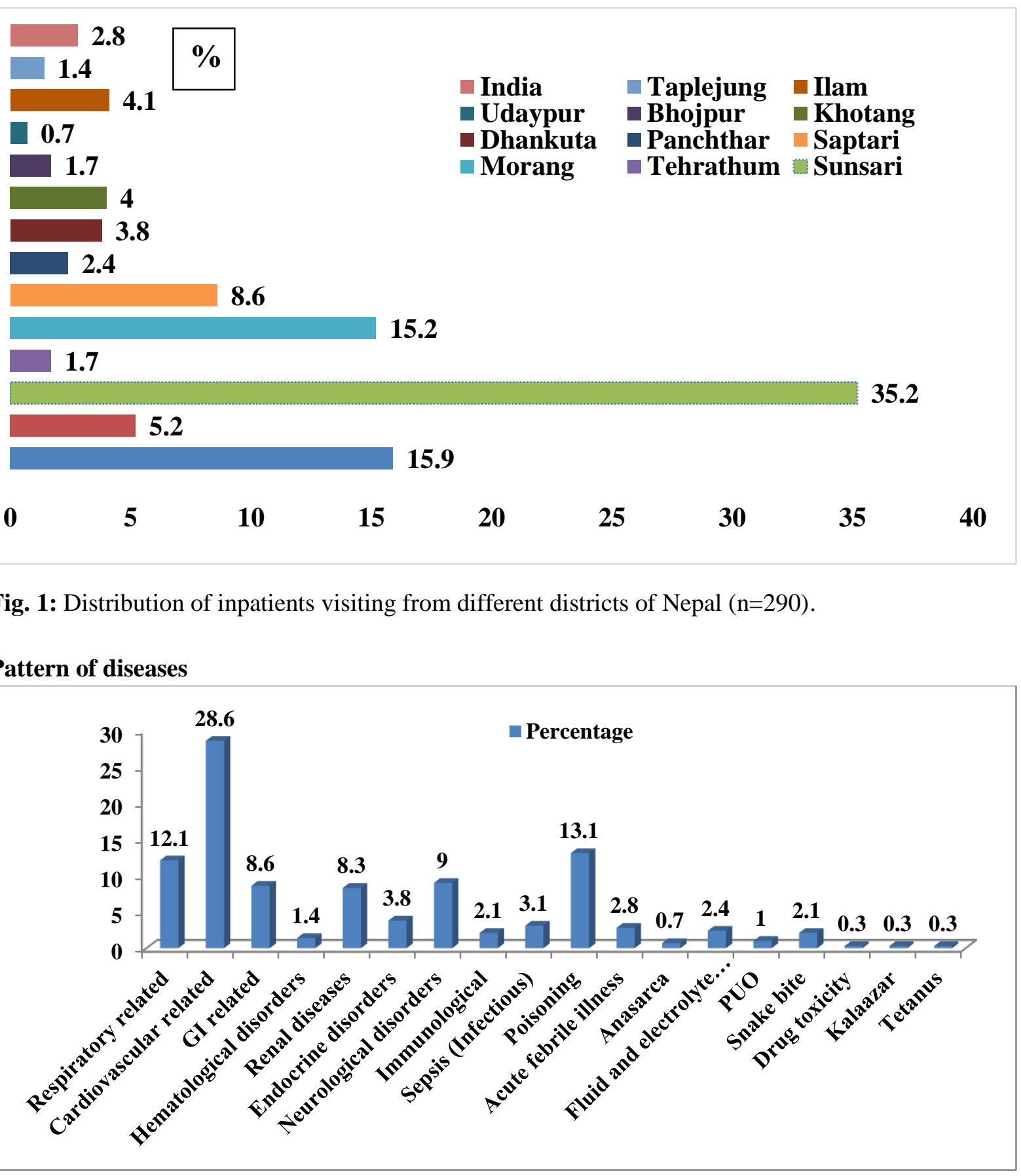

Fig. 2: Pattern of diseases reported among inpatients $(n=290)$.

Mode of admission

\begin{tabular}{|l|c|c|}
\hline Table 2: Mode of admission of inpatients $(\mathrm{n}=290)$. \\
\hline Mode of admission & Frequency & Percentage \\
\hline Outpatient department (OPD) & 43 & 14.8 \\
\hline Emergency & 193 & 66.5 \\
\hline Transfer from other wards & 24 & 8.3 \\
\hline Transfer from ICU/CCU & 30 & 10.4 \\
\hline
\end{tabular}




\section{Nursing care provided}

\begin{tabular}{|c|c|c|}
\hline Nursing care & Frequency & Percentage \\
\hline \multicolumn{3}{|l|}{ General care } \\
\hline I/V cannula site care & 144 & 49.7 \\
\hline Back care & 22 & 7.6 \\
\hline Intake output & 290 & 100.0 \\
\hline Personal hygiene & 264 & 91.03 \\
\hline Sponge bath & 27 & 9.3 \\
\hline Health education on particular disease & 42 & 14.5 \\
\hline Psychological support & 119 & 41.0 \\
\hline Passive exercise & 7 & 2.4 \\
\hline Ambulation & 25 & 8.6 \\
\hline Chest physiotherapy & 11 & 3.7 \\
\hline \multicolumn{3}{|l|}{ Specific care } \\
\hline Positioning-propped up & 105 & 36.2 \\
\hline Watch for oxygen toxicity & 27 & 9.3 \\
\hline 2 hourly position change & 68 & 23.4 \\
\hline Watch for UGI bleeding & 10 & 3.4 \\
\hline Dressing for thrombophlebitis & 1 & 0.3 \\
\hline Catheter care & 20 & 6.9 \\
\hline Observe for bradycardia & 1 & 0.3 \\
\hline Endotracheal tube care & 1 & 0.3 \\
\hline Cardiac monitoring & 5 & 1.7 \\
\hline Weight monitoring & 9 & 3.1 \\
\hline Leg elevation & 2 & 0.7 \\
\hline Abdominal girth charting & 3 & 1.0 \\
\hline Cold sponging & 2 & 0.6 \\
\hline $\mathrm{SPO}_{2}$ monitoring & 36 & 12.41 \\
\hline N/G tube feeding & 4 & 1.2 \\
\hline ECG & 4 & 1.2 \\
\hline Diabetic foot care & 1 & 0.3 \\
\hline Preoperative care for CAG & 6 & 2.1 \\
\hline RBS monitoring & 41 & 14.13 \\
\hline Wound Care & 2 & 0.6 \\
\hline
\end{tabular}

Nursing care provided to inpatients were divided to general care and specific care which is shown in table 3. Majority (91.03\%) of inpatients received the care related to maintenance of personal hygiene (hair care, nail care, oral care and grooming). Intravenous cannula (I/V) site care was provided to $49.7 \%$ of the inpatients based on their need. Maintenance of intake output pattern was received by all patients. Forty one percent of the patients were provided reassurance while almost $15 \%$ inpatient received health education on particular disease.

Concerning specific nursing care $36.2 \%$ patients were provided to maintain their position to ease their breathing, $23.2 \%$ were changed position 2 hourly and SPO2 monitoring was done among $12.41 \%$. 


\section{Outcome of patients}

\begin{tabular}{|l|c|c|}
\hline Table 4: Outcome of inpatients (n=290). \\
\hline Outcomes & Frequency & Percentage \\
\hline Recovered and discharge & 223 & 76.9 \\
\hline Expired & 10 & 3.4 \\
\hline Leave against medical advice (LAMA) & 14 & 4.8 \\
\hline Discharge on patient request (DOPR) & 19 & 6.6 \\
\hline Refer to another hospital & 3 & 1 \\
\hline Transfer to another ward & 14 & 4.8 \\
\hline Transfer to ICU/CCU & 7 & 2.4 \\
\hline Duration of hospital stay & Range: 1 -35 days & Median: 4 days \\
\hline
\end{tabular}

\section{Discussion}

A hospital based cross-sectional study was conducted in medical ward of B. P. Koirala Institute of Health Sciences. Admission record book was reviewed thoroughly and checked for completeness of the record of which 290 patients having complete records were enrolled for the study. In present study, majority $(91.03 \%)$ of inpatients received the care related to maintenance of personal hygiene (hair care, nail care, oral care and grooming). Oral care is one of the important nursing care among inpatients of medical ward. In a systematic review, it was found that oral hygiene have an impact on incidence and outcomes of respiratory diseases like pneumonia and chronic obstructive pulmonary disease in people living in the community and in long-term health care facilities. Such incidence can be reduced by oral hygiene measures [11]. Similarly another study conducted in Canada supports the importance of oral care that explains a positive body image and the perception of adequate oral health are linked to increased social contacts, as well as improved health and well-being irrespective of age [12]. A study reported that oral health have an impact on daily performances where they identified difficulty of eating and enjoying food (42.3\%), and speaking and pronouncing clearly (10.3\%)due to inadequate oral care [13]. Thus nursing personnel should provide oral care as it is one of the important nursing care to improve overall patient outcome at hospitals.

In this study, one third of patients received specific nursing care that is two hourly position change. This is an important specific nursing care for bed ridden patients to prevent pressure sores which was evident by a research conducted at Sweden where nursing staff used to reposition the patients who were high risk than those assessed as low risk. This led to the conclusion that repositioning and positions used in the prevention of pressure ulcers is important [14]. A research study found that, patients were repositioned frequently during the day and evening and least at night time [15]. Pressure ulcers can predispose to a variety of complications that include bacteremia, osteomyelitis, squamous cell carcinoma, and sinus tracts. The three components of pressure ulcer prevention that must be considered in any patient include management of incontinence, nutritional support, and pressure relief. Various electronic devices and materials have been practiced to prevent pressure ulcer [16]. However in low income countries where such devices can't be affordable and approachable carefully 
planned nursing care can contribute to prevent the pressure sores. In this study, intravenous cannula site care was provided to $49.7 \%$ of the inpatients based on their need. Similar finding was revealed in a hospital based study conducted at Johor, Malaysiawhere $83.7 \%$ followed the correct practice of care and maintenance of IV cannula. The researcher also suggested that nurses should know about this vital procedure in order to prevent risk and complication to the patient. Therefore, IV cannula site care is one of the important nursing care and it should be followed correctly [17]. In this study maintenance of intake output was received by all patients. A research suggested that advanced heart failure, renal diseases are often associated with a variety of hemodynamic, fluid, and electrolyte derangements. This involves vigilant assessment of hydration, fluid treatment plan personalized for the specific patient, repeated and frequent reassessment of fluid and electrolyte balance, and appropriate changes in the treatment plan in response to the rapidly changing clinical situation of the patient that cannot be maintained by clinicians along. Hence Nursing care is utmost to such patients [18]. It helps the inpatients for better clinical outcome. In the present study $36.2 \%$ patients were kept in propped up position to ease their breathing and SPO2 monitoring was done among $12.41 \%$. Likewise study conducted in Australia found elevation of the head of the bed $\left(1-45^{\circ}\right)$ was the most frequently adopted position[15]. Present study also identified catheter care(6.9\%), chest physiotherapy (3.7\%), ambulation (8.6\%), nasogastric tube feeding (1.2\%), preoperative care $(2.1 \%)$ and diabetic foot care $(0.3 \%)$ as important nursing care provided to the patient. Forty one percent of the patients were provided psychological support while almost $15 \%$ inpatient received health education on particular disease. In a study the mean total 'Satisfaction with Nursing Care Scale' score was $62.08 \pm 20.94$, and the mean total 'Experience of Nursing Care Scale' was $71.97 \pm 11.97$. The highest satisfaction items were reported as 'the skillfulness of nurses' and 'the nurses' respect for the patients' privacy' concluding that patients require more individualized care from nurses regarding education, communication and comfort [19]. This suggests that nursing care is fundamental for patient satisfaction and positive image with hospital environment, rapid recovery and wellbeing. Additionally, this study found that almost 8 out of 10 patients were recovered and discharged. The World Alliance for Patient Safety reported that $10 \%$ of hospital patients in developed countries suffer an adverse event each year [20]. This is a good sign of care. Patient outcome depends upon care provided by various discipline that is medical doctors, nursing professionals, paramedics, supporting staffs and even administration. It is evident that, nursing care is vital for better prognosis. In support to this, a research found that routine use of care maps was used to minimize unnecessary patient death [9].

\section{Conclusion}

Maintenance of personal hygiene, intravenous cannula site care, psychological support and two hourly positioning were common practice performed.

\section{Recommendations}

Individual level disease specific nursing care research needs to be done in a large setting. Nursing care practices should be studied by using various nursing care tools and guidelines to identify the applicability and effectiveness.

\section{Limitation of the Study}

This research could not identify individual level nursing care based on disease pattern. The impact on patient outcome due to nursing care could not be established. 


\section{Acknowledgement}

The authors would like to acknowledge nursing officer and ward staffs of medical ward of B. P. Koirala Institute of Health Sciences, Dharan.

\section{Conflict of Interest}

We declare no conflict of interest.

\section{Financial Disclosure}

No grant or financial support has been received for this research work.

\section{References}

[1] T. Jasmine, Art, science, or both? Keeping the care in nursing, The Nursing clinics of North America 44(4) 2009415-21. PubMed PMID: 19850178. Epub 2009/10/24. eng.

[2] P. F. Martins, M.G. Perroca, Care necessities: the view of the patient and nursing team, Revista brasileira de enfermagem 70(5) ( 2017) 1026-32. PubMed PMID: 28977230. Epub 2017/10/05. eng

[3] K. Wilkin, The meaning of caring in the practice of intensive care nursing, British Journal of Nursing 12(20) ( 2003) 1178-85.

[4] J. A. Connor, S. Mott, A. Green, C. Larson, P. Hickey, Measurement of Quality of Nursing Practice in Congenital Cardiac Care, American journal of critical care : an official publication, American Association of Critical-Care Nurses 25(2) ( 2016) 128-35. PubMed PMID: 26932914. Epub 2016/03/05. eng.

[5] J. Desborough, C. Phillips, M. Banfield, N. Bagheri, J. Mills, Impact of nursing care in Australian general practice on the quality of care: A pilot of the Patient Enablement and Satisfaction Survey (PESS), Collegian (Royal College of Nursing, Australia) 22(2) ( 2015) 207-14. PubMed PMID: 26281409. Epub 2015/08/19. eng.

[6] H. Bragadottir, B. J. Kalisch, G. B. Tryggvadottir, Correlates and predictors of missed nursing care in hospitals, Journal of clinical nursing 26(11-12) (2017) 1524-34. PubMed PMID: 27325454. Epub 2016/06/22. eng.

[7] R.J. Piscotty, Jr., B. Kalisch, The relationship between electronic nursing care reminders and missed nursing care, Computers, informatics, nursing : CIN 32(10) (2014) 475-81. PubMed PMID: 25119428. Epub 2014/08/15. eng.

[8] L.H. Aiken, H.L. Smith, E.T. Lake, Lower Medicare mortality among a set of hospitals known for good nursing care, Medical care 32(8) (1994) 771-87. PubMed PMID: 8057694. Epub 1994/08/01. eng.

[9] A.E. Tourangeau, D.M Doran, L.M. Hall, Pallas L. O'Brien, D. Pringle, J.V. Tu, et al., Impact of hospital nursing care on 30 day mortality for acute medical patients, Journal of advanced nursing 57(1) ( 2007) $32-44$.

[10] J. Desborough, N. Bagheri, M. Banfield, J. Mills, C. Phillips, R. Korda, The impact of general practice nursing care on patient satisfaction and enablement in Australia: A mixed methods study. International journal of nursing studies 64 (2016) 108-19. PubMed PMID: 27768985. Epub 2016/10/22. eng.

[11] D. Manger, M. Walshaw, R. Fitzgerald, J. Doughty K. L. Wanyonyi, S. White, et al., Evidence summary: the relationship between oral health and pulmonary disease, British dental journal 222(7) (2017) 527-33. PubMed PMID: 28387268. Epub 2017/04/08. eng.

[12] L.R. Donnelly, L.H. Clarke, A. Phinney, M.I. MacEntee, The impact of oral health on body image and social interactions among elders in long-term care, Gerodontology 33(4) (2016) 480-9. PubMed PMID: 25664900. Epub 2016/10/26. eng.

[13] P. Andersson, J. Kavakure, P. Lingstrom, The impact of oral health on daily performances and its association with clinical variables in a population in Zambia, International journal of dental hygiene 15(2) (2017) 128-34. PubMed PMID: 26283168. Epub 2015/08/19. eng. 
[14] U. Kallman, S. Bergstrand, A. C. Ek, M. Engstrom, M. Lindgren, Nursing staff induced repositionings and immobile patients' spontaneous movements in nursing care, International wound journal 13(6) (2016) 1168-75. PubMed PMID: 25779932. Epub 2015/03/18. eng.

[15] S. Latimer, W. Chaboyer, B. M. Gillespie, The repositioning of hospitalized patients with reduced mobility: a prospective study, Nursing open 2(2) (2015) 85-93. PubMed PMID: 27708804. Pubmed Central PMCID: PMC5047314. Epub 2015/07/14. eng.

[16] S. Latimer, W. Chaboyer, B. Gillespie, Pressure injury prevention strategies in acute medical inpatients: an observational study, Contemporary nurse 52(2-3) (2016) 326-40. PubMed PMID: 27228380. Epub 2016/05/27. eng.

[17] I. F. Arbaee, Ahmad Nizal Mohd Ghazali, Nurses Knowledge and Practice Towards Care and Maintenance of Peripheral Intravenous Cannulation in Pantai Hospital, Batu Pahat, Johor, Malaysia, Malaysia: Open University Malaysia, 2014.

[18] T. M. Kear, Fluid and Electrolyte Management Across the Age Continuum, Nephrology nursing journal :journal of the American Nephrology Nurses' Association 44(6) (2017) 491-6. PubMed PMID: 29281773. Epub 2017/12/28. eng.

[19] E. Kol, F. Arıkan, E. İlaslan, M.A. Akıncı, M.C. Koçak, A quality indicator for the evaluation of nursing care: determination of patient satisfaction and related factors at a university hospital in the Mediterranean Region in Turkey, Collegian (Royal College of Nursing, Australia) 25(1) (2018) 51-6.

[20] World Health Organization, World Alliance for Patient Safety: Forward Programme, 2004. 